\title{
USO DE PLANILHAS ELETRÔNICAS PARA A APRENDIZAGEM DE ESTATÍSTICA
}

USE OF ELECTRONIC SCHEDULES FOR STATISTICAL LEARNING

\author{
Katia Alves Campos ${ }^{1}$ \\ Roger Henrique Silva ${ }^{2}$ \\ Roberto Luiz de Azevedo ${ }^{3}$
}

\begin{abstract}
Resumo: Neste texto pretende-se relatar a experiência de um minicurso em que conteúdos de Estatística são tratados com auxílio de planilhas eletrônicas, com foco na desmistificação da estatística básica e adaptação desse conteúdo para tomada de decisões. Buscou-se usar as planilhas eletrônicas como ferramenta para trabalhar conceitos estatísticos e ao mesmo tempo desenvolver o pensamento estatístico. O uso das planilhas para o cálculo das estimativas possibilitou ofertar a alunos de nível médio tópicos de estatística com uma profundidade que só é abordada em nível de graduação. A participação no minicurso foi considerada satisfatória pelos envolvidos, que julgaram ter aprendido os conteúdos e serem capaz de aplicá-los no dia-a-dia e estarem aptos para desenvolver projetos de iniciação científica. Devido aos resultados, pode-se propor um projeto de extensão não só para testar a metodologia a alunos das séries finais do Ensino Fundamental e Ensino Médio como também para a capacitação de professores de Educação Básica.
\end{abstract}

Palavras-chave: Integração; Formulação de hipóteses; Educação Estatística.

Abstract: This paper intends to report the experience of a mini-course in which Statistics contents are treated with the help of electronic spreadsheets, focusing on the demystification of basic statistics and adapting this content for decision making. The use of the spreadsheets for the calculation of the estimates made it possible to offer to students of intermediate level topics of statistics with a depth that is only approached at graduation level. Participation in the mini-course was considered satisfactory by those involved, who thought they had learned the contents and were able to apply them on a daily basis and to be able to develop scientific initiation projects. Due to the results, it is possible to propose an extension project not oinly to test the methodology for School and High School as well as for the qualification of teachers of Basic Education.

Keywords: Integration; Hypothesis formulation; Statistical Education.

\footnotetext{
${ }^{1}$ Doutora em Estatística e Experimentação Agropecuária pela Universidade Federal de Lavras (UFLA). Docente do Instituto Federal do Sul de Minas Gerais (IFSULDEMINAS), Machado, Minas Gerais, Brasil. E-mail: katia.campos@ifsuldeminas.edu.br

${ }^{2}$ Bacharelando em Agronomia pelo Instituto Federal do Sul de Minas Gerais (IFSULDEMINAS), Machado, Minas Gerais, Brasil. E-mail: roger.rhs94@gmail.com

${ }^{3}$ Doutor em Ciências pela Universidade Federal de Lavras (UFLA). Docente do Instituto Federal do Sul de Minas Gerais (IFSULDEMINAS), Machado, Minas Gerais, Brasil. E-mail: roberto.azevedo@ifsuldeminas.edu.br
} 


\section{Introdução ao estudo}

O Instituto Federal de Educação, Ciência e Tecnologia do Sul de Minas Gerais (IFSULDEMINAS), desde sua criação em 2008 busca, com o auxílio da excelência na educação profissional e tecnológica, formar cidadãos capacitados, competentes e criativos.

De modo a atuar no tripé Ensino, Pesquisa e Extensão, a comunidade escolar propõe atividades que possam expandir o raio de atuação da Instituição, dessa forma são propostos projetos de pesquisa e extensão que possam disseminar as atividades e atingir cada vez mais a comunidade geral.

Uma atividade institucional interna é a iniciação científica, que acontece tanto no nível médio quanto no nível superior, e na qual são desenvolvidos projetos que vão desde revisões literárias a desenvolvimento de novos produtos e técnicas, possibilitando a integração entre níveis de ensino e capacitação integral dos envolvidos.

Principalmente nos discentes de nível médio, pode-se observar a influência da participação nessas atividades de pesquisa no desenvolvimento integral dos envolvidos; pois para desenvolver as pesquisas, principalmente aquelas que envolvem técnicas experimentais, o discente é forçado ao contato com conteúdos diversos, que naturalmente não fazem parte do programa de nível médio.

A partir dessa percepção da capacidade dos envolvidos em iniciação científica de nível médio em tomar decisões baseados em estimativas estatísticas, e não simplesmente no empirismo, quando estimulados por problemas reais, que precisam de inferências, pois não se caracterizam apenas como uma lista de exercícios cujo objetivo é chegar a uma resposta conhecida, foi proposto um minicurso, em 2018, em que a comunidade escolar interessada pôde trabalhar conteúdos de estatística, com auxílio de planilhas eletrônicas.

O objetivo deste texto é relatar o desenvolvimento e resultados de um minicurso ofertado a comunidade escolar do IFSULDEMINAS, Campus Machado em 2018. Durante os encontros, num total de 28 horas, tentou-se desmistificar a estatística básica, adaptar o conteúdo de estatística para tomada de decisões utilizando como auxílio as planilhas eletrônicas e aprofundar a literácia estatística com ênfase ao raciocínio lógico, buscou-se, ainda, usar as planilhas eletrônicas como ferramenta para trabalhar conceitos estatísticos e ao mesmo tempo desenvolver o pensamento estatístico. 


\title{
2 Referencial teórico
}

É na graduação que existem disciplinas nomeadas "Estatística”, entretanto com o passar do tempo os conteúdos da disciplina vêm ganhando importância também fora dos meios acadêmicos para tomada de decisões. Tanto governos quanto a iniciativa privada utilizam seus métodos robustos para melhorar processos e otimizar investimentos. Uma definição do termo estatística aparece em Ignácio (2010, p. 79):

\begin{abstract}
A estatística é definida como um conjunto de métodos e técnicas que envolve todas as etapas de uma pesquisa, desde o planejamento, coordenação, levantamento de dados por meio de amostragem ou censo, aplicação de questionários, entrevistas e medições com a máxima quantidade de informação possível para um dado custo, até a consistência, processamento, organização, análise e interpretação de dados para explicar fenômenos socioeconômicos; inferência, cálculo do nível de confiança e do erro existente na resposta para uma determinada variável e disseminação das informações.
\end{abstract}

Embora seja um conjunto de métodos considerados acadêmicos, os cidadãos comuns diariamente veem nos meios de comunicação muitas informações que são fundamentadas em conceitos estatísticos. Principalmente em períodos eleitorais, os termos estatísticos são repetidos em todos os telejornais.

A utilização crescente desses conceitos no dia-a-dia, impactam na necessidade de entendê-los e segundo Silva, Diniz e Carmo (2017), cabe aos professores utilizar meios didáticos diversos de forma a tornar acessível aos alunos ferramentas simples que possibilitem uma maior compreensão sobre a interpretação da estatística e sua aplicação.

Nesse contexto, a educação estatística passou a figurar nos projetos pedagógicos escolares do Brasil como parte da disciplina de Matemática desde o primeiro ciclo do Ensino Fundamental e no nível médio os livros didáticos trazem normalmente capítulos que contém seus conteúdos.

Nos projetos pedagógicos dos cursos técnicos integrados ao Ensino Médio, no Instituto Federal do Sul de Minas (IFSULDEMINAS), Campus Machado, por exemplo, a educação estatística também está inserida na disciplina de Matemática e está prevista para o segundo ano no curso de Agropecuária (IFSULDEMINAS, 2016a), no curso de Alimentos (IFSULDEMINAS, 2016b) e no curso em Informática (IFSULDEMINAS, 2016c). Nesse último, além da abordagem em Matemática também há uma disciplina, Softwares Aplicativos, no primeiro ano em que há o estudo de Estatística integrado ao estudo de planilhas eletrônicas. 
DOI: http://dx.doi.org/10.33238/ReBECEM.2019.v.3.n.2.22635

Campos, Wodewotzki e Jacobini (2013) afirmam que a Educação Estatística difere em método da Educação Matemática e definem em seu texto três competências a serem desenvolvidas pela Educação Estatística:

\footnotetext{
Literácia estatística pode ser vista como o entendimento e a interpretação da informação estatística apresentada. Raciocínio estatístico representa a habilidade para trabalhar com as ferramentas e os conceitos aprendidos. Pensamento estatístico leva a compreensão global da dimensão do problema permitindo ao aluno questionar espontaneamente a realidade observada por meio da Estatística (CAMPOS; WODEWOTZKI; JACOBINI, 2013, p. 1920).
}

Percebe-se que as competências a serem desenvolvidas pela Educação Estatística estão interligadas e passam pelo entendimento das questões que podem ser resolvidas por técnicas estatísticas (literácia estatística), capacidade de utilizar os conceitos da disciplina para resolução de problemas com o auxílio das ferramentas disponíveis (raciocínio estatístico) e um entendimento global que questiona o mundo (pensamento estatístico).

São competências complexas que a simples resolução de listas de exercícios, com o objetivo de chegar a uma resposta, pode não ser capaz de desenvolver. Silva, Martins e Campos (2019) afirmaram, nesse sentido, que com o uso das tecnologias para aprofundamento de conceitos pode-se "estimular o raciocínio lógico com foco na resolução de problemas e não na simples realização de cálculos".

O desenvolvimento dessas três competências pode não ser completo, principalmente porque os problemas/desafios apresentados nos livros didáticos não partem do interesse dos educandos. Os conteúdos estatísticos, normalmente são capítulos dos livros de Matemática do nível médio de ensino, e normalmente seguem a mesma apresentação, em que os conteúdos são definidos, com exemplos de exercícios resolvidos são exemplificados e depois seguem listas de exercícios em que os discentes devem chegar a uma resposta correta, tida como única.

Existe uma tendência de abordar problemas reais nos exercícios que são propostos nos livros didáticos, por exemplo, pode-se citar a dissertação de Tiribio (2015, p.7) que estudou a evolução dos livros didáticos de Matemática no Brasil e concluiu que "a análise dos livros didáticos demonstrou mudanças significativas em relação a forma de apresentação dos conteúdos".

Mais precisamente sobre os conteúdos de estatística, Santos e Alvarenga (2014) analisaram um livro e classificaram-no como adequado quanto aos parâmetros dos livros didáticos e que pode ser considerado bem estruturado. Entretanto, corroborando com o que é defendido neste texto, os autores indicam que faltam sugestões de recursos 


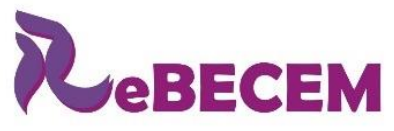

DOI: http://dx.doi.org/10.33238/ReBECEM.2019.v.3.n.2.22635

tecnológicos e que falta a abordagem, no manual dos professores, da elaboração de projetos de pesquisa.

Assim, percebe-se que mesmo com a tendência de utilizar exemplos que possam acontecer no dia-a-dia, a abordagem de projetos de pesquisa ainda não configura como realidade. Embora essa técnica seja consenso entre os textos específicos de Educação Estatística, pois ao desenvolver pesquisas que partam do interesse dos discentes, é a forma mais eficaz de desenvolver o pensamento estatístico, pois integra a literácia estatística com a busca de ferramentas e técnicas capazes de consolidar o raciocínio estatístico.

Ao desmistificar os conceitos de estatística básica, com a aplicação de seus conteúdos em interesses pessoais, pode-se proporcionar meios para que os interessados possam continuar aprendendo e aprofundando o conhecimento. Esse processo pode possibilitar uma melhora na criticidade e capacitar o estudante na continuidade dos estudos.

\section{A dinâmica da experiência}

Em 2018, devido ao volume da divulgação na mídia de resultados das pesquisas eleitorais em que o termo "estatisticamente empatados" retornou ao dia-a-dia de todos os brasileiros, era possível perceber que muitos na comunidade escolar do IFSULDEMINAS - Campus Machado aceitavam como verdade, mas não entendiam verdadeiramente todo o processo necessário para que a afirmação pudesse ser feita. Entretanto, outros não confiam na informação, pois pensavam e até verbalizavam "Como? 32\% pode ser igual a 35\%?".

$\mathrm{Na}$ Instituição, existe um período livre, quartas-feiras à tarde, destinado à realização de projetos de ensino/pesquisa/extensão, de modo a possibilitar a formação integral do discente.

Surgiu a ideia de aproveitar o interesse natural despertado pelos resultados das pesquisas eleitorais sobre a intenção de votos e idealizou-se um minicurso de quatro horas, em que seriam abordados os conteúdos estatísticos necessários para a construção dos intervalos de confiança, com auxílio de planilhas eletrônicas. Também foram abordadas as etapas do método científico em que cada hipótese deve gerar um objetivo específico e, correspondentemente, uma metodologia que envolve, na maioria das vezes, uma técnica estatística para testar a hipótese inicial. 


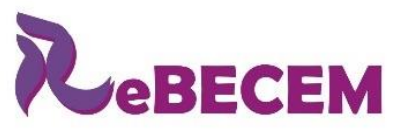

DOI: http://dx.doi.org/10.33238/ReBECEM.2019.v.3.n.2.22635

A ideia era fazer o minicurso para os alunos do curso técnico de nível médio em Alimentos, porque esses não têm a disciplina de Introdução à Informática e, portanto, pouco contato, na Instituição, com ferramentas que possam auxiliar na aplicação dos conteúdos estatísticos estudados na disciplina de Matemática.

$\mathrm{O}$ interesse foi maior do que o esperado, participaram servidores e alunos de graduação. As discussões foram tão produtivas, que surgiu dos envolvidos o pedido de aprofundar o tema.

Encaminhou-se então a todos os presentes um questionário (ANEXO I), que apresentava a proposta de ampliação do minicurso em mais seis encontros de quatro horas cada e as datas dos próximos encontros. Foram enviadas treze questões, em que a primeira pergunta era: "Você quer continuar a participar do curso". E as outras questões giravam em torno de informações pessoais, que foram utilizadas para criar hipóteses simples que seriam testadas com o uso de planilhas eletrônicas para o cálculo das estatísticas.

Por exemplo, a primeira hipótese $(\mathrm{H} 1)$ relativa a primeira pergunta é: “ $H 1: O$ questionário será respondido principalmente por aqueles que tiverem interesse em continuar o curso, porque aqueles que não quiserem ou que não tiverem disponibilidade nas datas e nos horários previstos não enviarão as respostas. ".

Assim após o período determinado para o retorno das respostas elas foram avaliadas e iniciou-se a extensão do minicurso.

Houve desistência de algumas pessoas no primeiro encontro da ampliação e como havia interesse de outros alunos na participação, esses foram convidados a participar dos demais encontros. Para possibilitar o acompanhamento, foi feita uma explanação sobre o curso para os novos participantes.

Durante o curso, foram abordados conceitos de estatística básica desde a montagem de tabelas de frequência, medidas de tendência central, medidas de variância, regressão, tabelas de contingência, coeficiente de contingência de Pearson (não paramétrico), intervalos de confiança para proporções, conteúdos que podem ser vistos entre outros em Ferreira (2009). Além da integração com a informática básica, em que foram utilizadas planilhas eletrônicas: conceitos básicos, funções estatísticas e gráficos. Editores de texto: conceitos básicos, tabelas e figuras. E, foram introduzidos os conceitos da normatização ABNT para apresentação de tabelas e figuras.

Ainda foi apresentado um aplicativo desenvolvido como forma de trabalho de conclusão de curso. Ao utilizar o aplicativo, os participantes puderam ampliar seus 
DOI: http://dx.doi.org/10.33238/ReBECEM.2019.v.3.n.2.22635

conhecimentos de medidas de tendência central de dados simples para dados agrupados e dados agrupados em classe (PAIVA; CAMPOS, 2019).

A estrutura do minicurso, após ampliação, pode ser resumida no Quadro 1, em que para cada encontro foram propostos conteúdos e objetivos específicos e no mínimo um meio para verificar se as metas e/ou objetivos específicos foram atingidos.

Quadro 1: Descrição dos conteúdos planejados para abordagem de estatística por meio de planilhas eletrônicas, IFSULDEMINAS, Campus Machado. 2018.

\begin{tabular}{|c|c|c|}
\hline $\begin{array}{l}\text { N. } \\
\text { encontro }\end{array}$ & $\begin{array}{l}\text { Conteúdo abordado } \\
\text { Metas e objetivos específicos }\end{array}$ & Meios de verificação dos resultados \\
\hline 1 & $\begin{array}{l}\text { - Introdução aos conceitos com apresentação das } \\
\text { técnicas em Datashow. } \\
\text { - Proposição de ampliação do curso. }\end{array}$ & Número de inscritos \\
\hline 2 & $\begin{array}{l}\text {-Diferenciação entre variáveis quantitativas e } \\
\text { qualitativas. } \\
\text {-Construção de tabelas de frequência simples para } \\
\text { variáveis qualitativas e quantitativas discretas. }\end{array}$ & $\begin{array}{l}\text { Separação das questões do } \\
\text { questionário em planilhas. } \\
\text { Montagem das tabelas de frequência }\end{array}$ \\
\hline 3 & - Medidas de tendência central e de dispersão. & $\begin{array}{l}\text { Cálculo das medidas para as } \\
\text { variáveis quantitativas. }\end{array}$ \\
\hline 4 & $\begin{array}{l}\text { - Extrapolação das medidas de tendência central } \\
\text { para dados agrupados. } \\
\text { - Criação de tabelas de frequência para dados } \\
\text { agrupados em classe para variáveis quantitativas } \\
\text { contínuas. }\end{array}$ & $\begin{array}{l}\text { Análise, agrupamento das variáveis } \\
\text { quantitativas contínuas em classes. }\end{array}$ \\
\hline 5 & $\begin{array}{l}\text { - Tabelas de contingência. } \\
\text { - Análise bivariada, variáveis qualitativas. } \\
\text { Coeficiente de contingência de Pearson (estatística } \\
\text { não paramétrica). }\end{array}$ & $\begin{array}{l}\text { Montagem das tabelas } \mathrm{de} \\
\text { frequência. } \\
\begin{array}{l}\text { Aplicação do coeficiente de } \\
\text { contingência. }\end{array}\end{array}$ \\
\hline 6 & $\begin{array}{l}\text { - Análise bivariada, variáveis quantitativas. } \\
\text { Regressão. } \\
\text { - Ajuste de reta utilizando gráfico de dispersão }\end{array}$ & $\begin{array}{l}\text { Uso de planilha eletrônica e inserção } \\
\text { de gráficos para análise. }\end{array}$ \\
\hline 7 & $\begin{array}{l}\text { - Intervalos de confiança para proporções. } \\
\text { - Técnicas de apresentação dos resultados em textos } \\
\text { e em apresentações visuais. } \\
\text { - Introdução as normas ABNT para tabelas e } \\
\text { gráficos e editores de texto. }\end{array}$ & $\begin{array}{l}\text { Cálculo de intervalos de confiança. } \\
\text { Montagem das tabelas e dos gráficos } \\
\text { dos resultados entre os integrantes. }\end{array}$ \\
\hline
\end{tabular}

$$
\text { Fonte: Elaborada pelos autores }
$$

No final do curso, foi encaminhado um segundo questionário aos concluintes para a avaliação do mesmo e a análise de continuidade da oferta em outras versões.

Após o primeiro encontro, que foi em uma sala de aula, todas as atividades foram desenvolvidas em laboratórios de informática, possibilitando a aplicação dos conteúdos diretamente nas planilhas eletrônicas.

\section{Resultados da experiência}

Para a realização do dia inicial do minicurso, foi lançado um convite, pelo envio de um link aos grupos de WhatsApp que têm ligação com a Instituição, por exemplo, grupos de turmas, professores e servidores. Foram inscritas 49 pessoas representados por 
DOI: http://dx.doi.org/10.33238/ReBECEM.2019.v.3.n.2.22635

6,1\% de professores de disciplinas diferentes de Matemática e 4,1\% de servidores; a grande maioria eram discentes $12,2 \%$ de nível superior e $77,6 \%$ alunos do curso técnico de nível médio em Alimentos.

Durante o encontro, foram apresentados exemplos de onde a estatística é utilizada na atualidade e com exemplos simples, contextualizados termos, como grau de liberdade. As estatísticas para média amostral, variância e desvio padrão foram desenvolvidas passo a passo e para finalizar apresentava-se o estimador. Percebeu-se que todos conseguiram entender que o estimador é necessário para se ter uma linguagem universal.

Após essa etapa, passou-se para a demonstração do uso de planilhas eletrônicas, para apresentação de dados, a primeira forma de apresentação está na Figura 1(a), em que após explicar o que significavam os dados, pediu-se para que os participantes tentassem descrever a tendência dos dados pelos números, houve algumas sugestões, entretanto alguém sugeriu apresentá-los por um gráfico, Figura 1 (b).

Figura 1: (a) Dados do lucro, em milhares de dólares, obtidos pela comercialização de softwares em função dos meses gastos para desenvolvê-lo. (b) Dispersão do lucro, em milhares de dólares, obtidos pela comercialização de softwares em função dos meses gastos para desenvolvê-los. Dados fictícios.

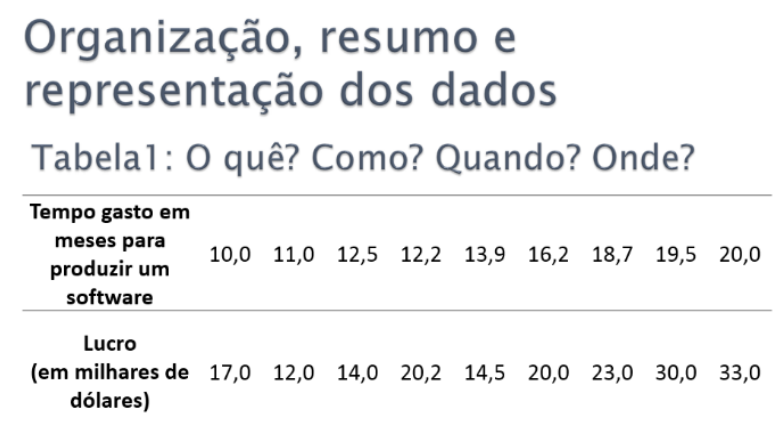

(a)

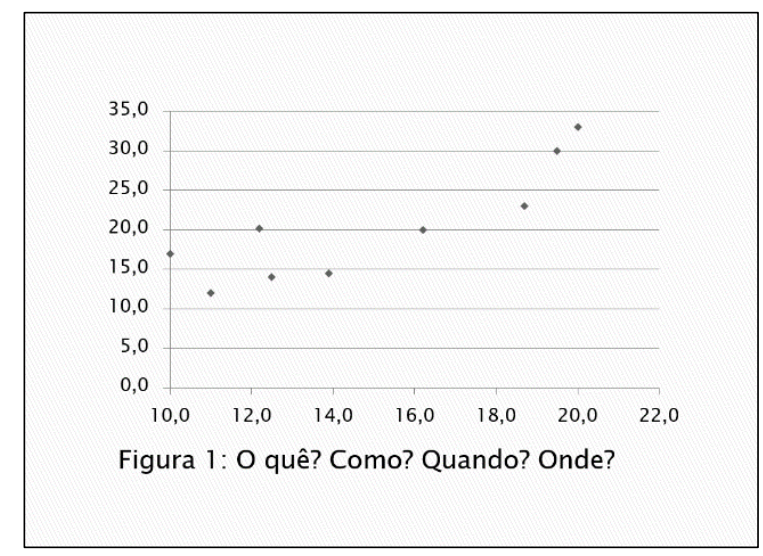

(b)

Fonte: Elaborada pelos autores

Quase que por unanimidade os participantes comentaram que era mais fácil entender que "quanto maior o tempo gasto para o desenvolvimento, maior o lucro obtido". Os que não conheciam as planilhas eletrônicas, ficaram interessados ao perceberem que após os dados tabulados, bastava a seleção dos mesmos e o uso de dois cliques para que o gráfico fosse plotado.

Embora tenham sido avisados que eram necessários testes para verificar se o ajuste de uma função poderia representar a situação, muitos preferiram a equação apresentada na Figura 2. $(y=1,62 x-3,73)$. Neste momento, pode-se revisar conteúdos de função 


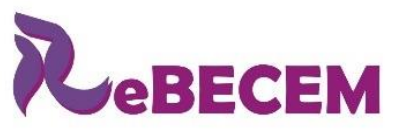

Revista Brasileira de Educação em
Ciências e Educação Matemática

DOI: http://dx.doi.org/10.33238/ReBECEM.2019.v.3.n.2.22635

afim, e como a ideia era de lucro o sinal negativo do coeficiente linear (-3.73) pode ser entendido como o investimento realizado para o desenvolvimento do software e o coeficiente angular $(1,62)$ como o aumento gerado para cada mês dedicado para o desenvolvimento do aplicativo.

Todas as etapas foram realizadas com auxílio de planilhas eletrônicas e mostrado passo a passo pela apresentação em um Datashow.

Acredita-se que neste momento foi o que mais despertou o interesse, porque os participantes acompanharam a plotagem dos dados com poucas etapas.

Figura 2: Representação do ajuste linear realizado com os participantes do minicurso, IFSULDEMINAS - Campus MACHADO, 2018

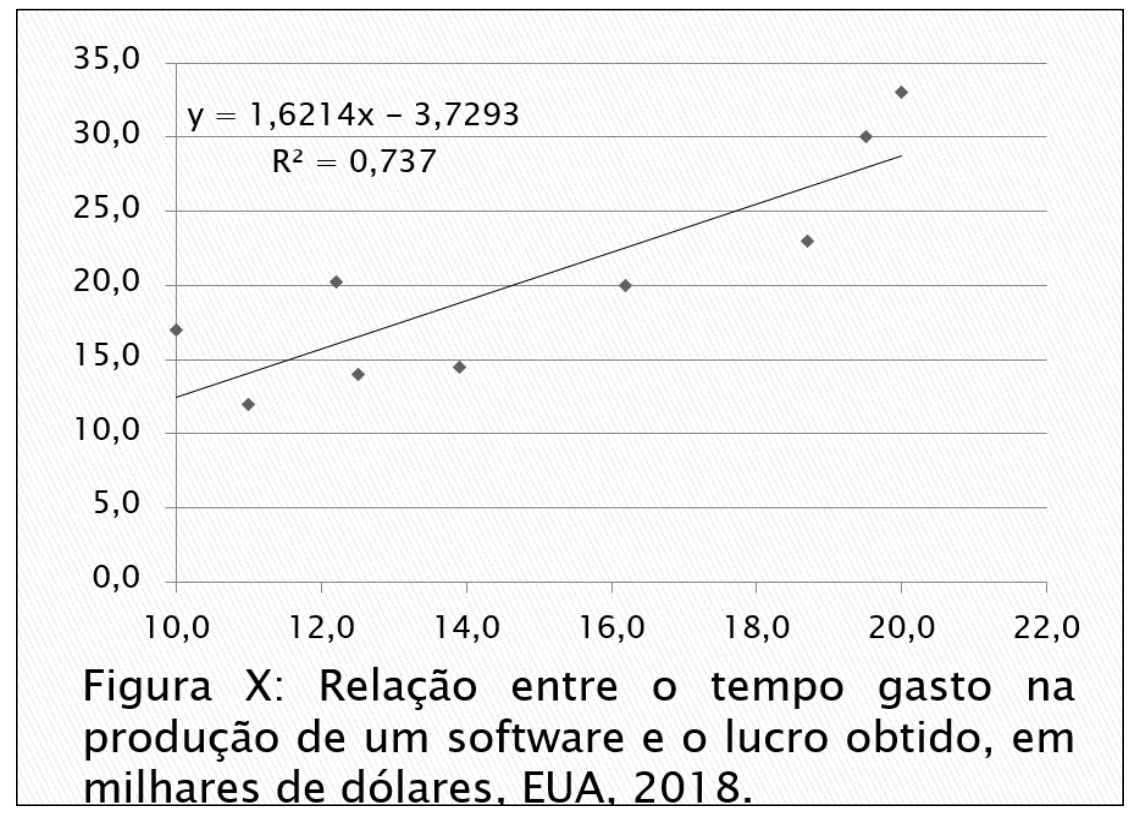

Fonte: Elaborada pelos autores

Ainda foram calculadas as estimativas das medidas de tendência central e de variância para os dados de lucro com a venda dos softwares, por meio do uso das funções já programadas nas planilhas, "MÍNIMO", "MÁXIMO", "MÉDIA", "VAR.A" e "DESV.PAD”, que respectivamente retornam as estimativas do valor mínimo, do valor máximo, da média, da variância e do desvio padrão. Ainda se calculou a amplitude com o uso da subtração do valor mínimo do valor máximo e o desvio padrão pedindo a raiz da variância.

Os participantes que não haviam se motivado pela plotagem do gráfico e respectivo ajuste do lucro obtido em função do tempo para o desenvolvimento do software, agora estavam interessados, vale ressaltar que mais de $75 \%$ dos participantes 
DOI: http://dx.doi.org/10.33238/ReBECEM.2019.v.3.n.2.22635

eram alunos do curso técnico em Alimentos de nível médio, que não tem em sua ementa Informática Básica. E que foram poucos que afirmaram ter algum contato anterior com planilhas eletrônicas.

A motivação foi tamanha que, como já relatado na dinâmica da experiência, surgiu o pedido de continuidade do minicurso, em que os participantes pudessem manipular as planilhas e não só observar sua manipulação.

Desse modo, foi enviado o questionário (ANEXO I), que foi feito com a opção Formulários do Google Docs. Houve o retorno de 41 respostas ao questionário, no período determinado, o que representou o interesse de $81,6 \%$ dos participantes em continuar o curso. Entretanto, no segundo encontro quatro servidores não compareceram. Abriram-se quatro vagas e essas foram preenchidas por discentes do curso técnico em Alimentos. E as reuniões aconteceram nas datas agendadas.

Iniciou-se o segundo encontro com a tabulação das idades dos presentes e a estimativa das medidas de posição e de dispersão semelhante ao que fora feito anteriormente.

Desde o segundo encontro, percebeu-se que a estrutura planejada e apresentada na Tabela 1, necessitaria ser repensada, pois a aprendizagem da planilha eletrônica tomou mais tempo que o previsto, por ser, para a maioria dos participantes o primeiro contato com essa ferramenta. Houve também interesse, quase que unânime dos discentes, em apresentar os resultados na forma de gráficos.

$\mathrm{Na}$ estrutura proposta esse tema seria abordado apenas no último encontro. Para contornar a dificuldade de manipulação das planilhas eletrônicas aproveitando o interesse dos envolvidos na inserção de gráficos, foram abordadas técnicas de representação em tabelas e gráficos das estatísticas estimadas paralelamente às aulas desde o segundo encontro. Foram também apresentadas as formas de transferência das tabelas e gráficos para editores de textos e a introdução a normatização ABNT para apresentação de tabelas e gráficos.

No segundo encontro foi apresentado o questionário que havia sido respondido pelos participantes, para exemplificar tipos de variáveis, e a partir daí os dados foram utilizados como material para aplicação dos conteúdos.

Normalmente, a diferenciação entre variáveis qualitativas e quantitativas causa certa confusão, mesmo entre os alunos de graduação, mas essa dificuldade não foi percebida entre os participantes. Não foi possível perceber se a situação foi beneficiada pela disposição dos laboratórios com bancadas de quatro computadores ou se porque 
DOI: http://dx.doi.org/10.33238/ReBECEM.2019.v.3.n.2.22635

havia mais dificuldade em utilizar os comandos para "copiar" e "colar" nas planilhas eletrônicas, mas pode-se afirmar com certeza que todos conseguiram fazer a separação mesmo apontando as subdivisões entre nominal e ordinal para as variáveis qualitativas e discreta e contínua para variáveis quantitativas.

A seguir foi utilizada a função "filtro" para quantificar as frequências simples das variáveis qualitativas e montar as tabelas de frequências simples, que foram representadas graficamente. Puderam ser exploradas as diferenças entre os gráficos de barras e/ou de colunas e aqueles que naturalmente devem ser apresentados em setores.

Entre todos os encontros era pedido que no intervalo até a próxima reunião, que os participantes procurassem aplicar os conhecimentos nas situações reais e refizessem as atividades explorando as ferramentas disponíveis,

No terceiro encontro retomou-se as principais medidas de tendência central e de variabilidade para treino com as variáveis quantitativas do questionário. Nesta etapa, percebeu-se que as funções são rapidamente aplicadas e que erros de digitação podem ser percebidos pela análise do resultado. Como o uso de "ponto" para separador de decimal não ser reconhecido como número.

Um exemplo que foi detectado automaticamente, pela maioria dos participantes, foi o erro de digitação na oitava pergunta “Qual é sua altura? ”. Como a opção de resposta no formulário era "resposta curta", a maioria respondeu na unidade metros, alguns responderam em centímetros escrevendo "cm" e uma pessoa escreveu em centímetros sem indicar a unidade. Assim, a média, mesmo após as correções dos "pontos" e transformação dos dados em centímetros para metros, continuava superior a cinco metros. A maneira de detectar qual célula estava com outro erro foi diversa, alguns olharam todos os dados, enquanto outros pediam o valor máximo e outros utilizavam o "filtro" para localizar e corrigir a digitação.

Outras variáveis também apresentaram problemas na resposta, e todos foram solucionados com as ferramentas de busca das planilhas eletrônicas, para depois iniciarem os cálculos das estatísticas.

O quarto encontro foi utilizado para retornar conceitos até então aprendidos para dados em lista e a apresentação do aplicativo para cálculo de medidas de tendência central, que foi desenvolvido por Paiva (2018) e testado e avaliado pelos participantes. O uso desse aplicativo no curso teve o objetivo da extrapolação das medidas para dados listados em rol, para dados agrupados e agrupados em classe. A extrapolação foi feita sem muitos transtornos, mesmo quando se tentou demonstrar as modificações nos estimadores 
DOI: http://dx.doi.org/10.33238/ReBECEM.2019.v.3.n.2.22635

(PAIVA; CAMPOS, 2019). Pesquisaram-se as técnicas indicadas para o agrupamento e testaram-se algumas, fazendo o agrupamento das medidas da altura, idade e peso. Após o agrupamento as estatísticas foram comparadas e pôde-se concluir que devido aos arredondamentos, algumas vezes são perdidas informações quando se trabalham dados agrupados em classe.

Nessa etapa o receio do uso de planilhas eletrônicas, quase não era notado. Ainda havia alguns comentários de que era muito conteúdo, mas que com pesquisa e consultas tudo era possível ser realizado.

No quinto encontro, tratou-se das tabelas de contingência. $O$ primeiro conceito introduzido foi o de "fileiras marginais", que correspondem ao total das tabelas de frequência simples. E por meio do uso do filtro, conseguiram construir as tabelas de contingência entre as variáveis qualitativas. No total eram possíveis quinze comparações, pois o questionário apresentou sete variáveis qualitativas, e uma delas teve $100 \%$ de respostas "sim", sendo, portanto, excluída da contagem. Neste momento pôde ser revisada por alguns e aprendida por outros a ideia de arranjo.

Passou-se então ao Coeficiente de Contingência de Pearson, que entre outros autores pode ser visto em Andrade e Ogliari (2010) e é estimado por:

$$
C^{*}=\frac{\sqrt{\frac{\chi^{2}}{\chi^{2}+n}}}{\sqrt{\frac{t-1}{t}}},
$$

onde: $\chi^{2}=\sum_{i=1}^{s} \sum_{j=1}^{r} \frac{\left(n_{i j}-e_{i j}\right)^{2}}{e_{i j}}, n_{i j}$ é a frequência acumulada para a característica em estudo na linha i e coluna $\mathrm{j}, e_{i j}$ corresponde a frequência esperada em caso de independência, n é o número de participantes da pesquisa, t o número mínimo dos níveis de cada classe em contingência, $r$ e s representam respectivamente o número dos níveis de cada característica tratada na linha i ou coluna j. Resumidamente, $C^{*}$ é um teste não paramétrico que pode ser utilizado para testar a associação de duas variáveis qualitativas ou entre variáveis contínuas discretas. Esse coeficiente toma valores entre zero e um, mas nunca atinge o valor um. $\mathrm{O}$ valor nulo corresponde ao caso em que se tem independência entre os resultados e os métodos utilizados. Valores diferentes de zero correspondem à associação mais forte entre as variáveis.

Foram testadas várias hipóteses de associação entre duas variáveis qualitativas das obtidas com o questionário (ANEXO I). Para exemplificar, utilizando a segunda e sexta perguntas, que são respectivamente, "Vamos nos dividir em duas turmas. Escolha a sua:" 


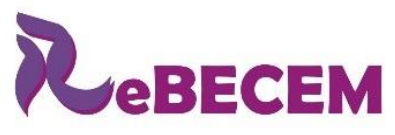

DOI: http://dx.doi.org/10.33238/ReBECEM.2019.v.3.n.2.22635
Revista Brasileira de Educação em

Ciências e Educação Matemática

ISSN 2594-9179

com duas opções de resposta e "Sexo" também com duas opções. Pôde ser formulada a Hipótese (H2): "H2: Não existe uma associação entre a escolha do horário para frequentar o curso e o sexo do participante, pois os horários são ambos no período vespertino". $\mathrm{H} 2$ pôde ser testada por meio do $\mathrm{C}^{*}$. Aplicando-se o estimador (1), obtémse o valor 0,07 e segundo os parâmetros do teste pode-se afirmar que não existem indicativos que H2 seja falsa, isto é, não existe associação entre o horário do curso e o sexo do participante.

Além da importância de testar as hipóteses, percebeu-se que os participantes não tiveram muita dificuldade em interpretar o estimador de $\mathrm{C}^{*}$, que embora seja mais complexo do que os até aqui apresentados - média, variância e desvio padrão, foi apresentado primeiramente como expressão, isto é, o estimador (1) e depois foi calculálo para associar algumas tabelas de contingência. Nesse processo todos os participantes conseguiram acompanhar a aplicação e reproduzi-la nas planilhas eletrônicas. Tal capacidade de acompanhamento e aplicação desse estimador leva a crer que se forem necessários testes diferentes, isto é, estatísticas diferentes, dos exemplos que foram abordados no curso, os alunos conseguirão aplicá-las a partir da pesquisa de outros estimadores e do acompanhamento de exemplos, permitindo que continuem a buscar alternativas de testes estatísticos por meio deconsultas a diversos outros testes.

No sexto encontro, foi apresentada a ideia de regressão, em que foram testadas as possibilidades de uma variável quantitativa contínua ser função de outra. As análises foram superficiais, sem o estudo das significâncias dos coeficientes, voltada muito mais para a aprendizagem das técnicas e formatação de gráficos.

No estudo de intervalo de confiança que foi o tema do último encontro, pôde-se perceber que os estimadores foram muito melhor aceitos e a ideia de margem de erro foi realmente apreendida.

Conforme já comentado, as apresentações dos resultados ocorreram simultaneamente devido ao interesse dos participantes.

Finalizado o minicurso, foi encaminhado o questionário de avaliação dele. Receberam o certificado, 31 discentes que representou $75,6 \%$ de efetividade. Todos os desistentes, sem exceção, justificaram a desistência por ter surgido outras atividades que não poderiam ser realizadas em outros dias e pediram para que fosse ofertado em outra ocasião outras versões do curso.

A pergunta que mais chamou a atenção foi "você acha que poderá aplicar os conhecimentos abordados no dia-a-dia", não houve respostas negativas, a maioria 


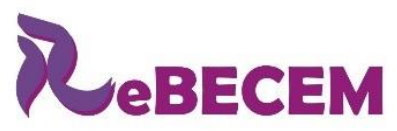

Revista Brasileira de Educação em

Ciências e Educação Matemática

DOI: http://dx.doi.org/10.33238/ReBECEM.2019.v.3.n.2.22635

$(73,3 \%)$ informou que se sentia capaz e os outros $26,7 \%$ que em partes se sentia capaz de aplicar o conhecimento no dia-a-dia.

Dentre os participantes do minicurso, atualmente 70,1\% participa de projetos de iniciação científica ou de projetos de extensão.

\section{Considerações finais}

Pode-se considerar que o minicurso foi efetivo na introdução dos participantes no estudo da estatística com auxílio de planilhas eletrônicas, foi possível ainda abordar conteúdos de Matemática e técnicas de editores de texto e introduzir a normatização da ABNT de tabelas e figuras.

Foi possível abordar conteúdos que normalmente não são temas de Ensino Médio e mesmo discentes com dificuldades na disciplina de Matemática conseguiram desenvolver sua literácia estatística com ênfase ao raciocínio lógico e visível desenvolvimento do pensamento estatístico.

O resultado foi tão inesperado, que mesmo ainda sem a finalização do minicurso, foi proposto um projeto de extensão que aprovou dois bolsistas, selecionados entre os participantes, para repassar os minicursos a dois grupos - um das séries finais do Ensino Fundamental e outro de Ensino Médio.

O objetivo atual é testar a metodologia para capacitação de professores, para o trabalho integrado que possibilite aumento da literácia estatística e proporcione aprendizagem de conteúdos distintos, pois pode-se perceber que as funções das planilhas eletrônicas foram absorvidas naturalmente, visto que eram necessárias para chegar a um resultado de interesse comum.

Agradecimento: Ao IFSULDEMINAS, pelo apoio para desenvolvimento do minicurso.

\section{Referências}

ANDRADE, D. F.; OGLIARI, P. O. Estatística para as ciências agrárias e biológicas. Com noções de experimentação. 2. ed. Florianópolis: Ed. da UFSC, 2010.

CAMPOS, C. R.; WODEWOTZKI, M. L. L.; JACOBINI, O. R. Educação estatística: teoria e prática em ambientes de modelagem matemática. 2. ed. Belo Horizonte: Autêntica, 2013.

IGNÁCIO, S. A., Importância da estatística para o processo de conhecimento e tomada de decisão. Revista Paranaense de Desenvolvimento, Curitiba, v. 31, n. 118, p. 175-192, jan./jun. 2010. Disponível em: 
DOI: http://dx.doi.org/10.33238/ReBECEM.2019.v.3.n.2.22635

http://www.ipardes.pr.gov.br/ojs/index.php/revistaparanaense/article/view/89/645. Acesso em: 16 maio. 2019.

FERREIRA, D. F. Estatística Básica. 2. ed. Lavras: UFLA, 2009.

INSTITUTO FEDERAL DO SUL DE MINAS GERAIS (IFSULDEMINAS). Projeto

Pedagógico do Curso Técnico em Agropecuária Integrado ao Ensino Médio. Machado, 2016a. Disponível em:

http://mch.ifsuldeminas.edu.br/images/stories/cursos/Matrizes_e_ppcs_tecnicos/PPC_Tec_Agro pecu\%C3\%A1ria_Int_2017_Final.pdf. Acesso em: 16 maio. 2019.

INSTITUTO FEDERAL DO SUL DE MINAS GERAIS (IFSULDEMINAS). Projeto Pedagógico do Curso Técnico em Alimentos Integrado ao Ensino Médio. Machado, 2016b. Disponível em:

http://mch.ifsuldeminas.edu.br/images/stories/cursos/Matrizes_e_ppcs_tecnicos/PPC_Tec_Alim entos_Int_2017_Final.pdf. Acesso em: 16 maio. 2019.

\section{INSTITUTO FEDERAL DO SUL DE MINAS GERAIS (IFSULDEMINAS). Projeto}

Pedagógico do Curso Técnico em Informática Integrado ao Ensino Médio. Machado, 2016c. Disponível em:

http://mch.ifsuldeminas.edu.br/images/stories/cursos/Matrizes_e_ppcs_tecnicos/PPC_Tec_Infor m\%C3\%A1tica_Int_2017_Final.pdf. Acesso em: 16 maio. 2019.

PAIVA, M. de. Software como ferramenta de apoio para aprendizagem das medidas de tendência central. 2018. Monografia (Sistemas de Informação) - Instituto Federal do Sul de Minas Gerais (IFSULDEMINAS), Machado, 2018.

PAIVA, M. de.; CAMPOS, K. A. APP para apoio do ensino de medidas de tendência central. In: CONGRESSO NACIONAL DE EDUCAÇÃO, 3., 2019, Poços de Caldas. Anais... Poços de Caldas: [s.n.], 2019. Disponível em: http://educacaopocos.com.br/Anais2019.html. Acesso em: 16 jun. 2019.

SANTOS, D. M. N.; ALVARENGA, K. B. Uma análise do conteúdo de estatística em um livro didático. Caminhos da Educação Matemática em Revista/ online, Aracajú, v. 2, n. 1, p. 123 134, set. 2014.

SILVA, M. F. da.; DINIZ, A. M.; CARMO, M. E. R. A. Despertando o olhar crítico estatístico no aluno da EJA. Educação, Cultura e Comunicação, São Paulo. v. 8, n. 15, p. 61-72, jan./jun. 2017. Disponível em: http://www.fatea.br/seer/index.php/eccom/article/viewFile/1706/1256 Acesso em: 8 maio. 2019.

SILVA, R. H., MARTINS, N. S. da, CAMPOS, K. A. Estatística uma adaptação do conteúdo de graduação. In: CONGRESSO NACIONAL DE EDUCAÇÃO. 3., 2019, Poços de Caldas.

Anais... Poços de Caldas: [s.n.], 2019. Disponível em:

http://educacaopocos.com.br/Anais2019.html. Acesso em: 16 jun.2019.

TURÍBIO. S. R. T. As mudanças ocorridas no livro didático de matemática e a sua influência na prática pedagógica do professor. 2015. Dissertação (Mestrado em Educação) Instituto de Ciências Humanas e Sociais, Universidade Federal de Mato Grosso, Rondonópolis, 2015. Disponível em:

http://ri.ufmt.br/bitstream/1/647/1/DISS_2015_Solange\%20Ramos\%20TeixeiraTuribio.pdf. Acesso em: 16 jun. 2019.

Recebido em: 16 de junho de 2019.

Aceito em: 13 de agosto de 2019. 
DOI: http://dx.doi.org/10.33238/ReBECEM.2019.v.3.n.2.22635

Anexo: Questionário utilizado para introduzir conceitos estatísticos

\section{Confirmação de inscrição no curso de estatística}

Se você está recebendo este link é porque participou ou se inscreveu para participar desse curso. A primeira pergunta é se você vai continuar. Para receber o certificado, você não pode faltar a dois encontros,

As datas de nossos encontros serão:

01/08; 15/08; 03/10; 24/10; 28/11 e 05/12, no laboratório 5 no prédio da Informática.

Obrigado por responder este questionário! Sua resposta é importante para nossa aprendizagem!

*Obrigatório

1. Você quer continuar a participar do curso?

Marcar apenas uma oval.

Sim

Não

2. Vamos nos dividir em duas turmas. Escolha a sua: *

Marcar apenas uma oval.

$13: 30$ às $15: 00$

$15: 30$ às $17: 00$

3. Qual é a renda per capta em sua casa? A renda per capta é calculada, somando todos os rendimentos e dividindo pelo número de pessoas que vivem deste dinheiro *

4. Como você se define *

Marcar apenas uma oval.

Branco.

Preto.

Pardo.

Amarelo.

Indigena.

5. Sua idade? *

6. Sexo *

Marcar apenas uma oval.

Feminino

Masculino

7. Peso * 
DOI: http://dx.doi.org/10.33238/ReBECEM.2019.v.3.n.2.22635

$10 / 06 / 2019$

8. Altura *

9. Número de irmãos - considere meio irmãos. *

10. Qual é sua relação com o Campus Machado *

Marcar apenas uma oval.
discente $1^{\circ}$ ano
discente $2^{\circ}$ ano
discente $3^{\circ}$ ano
discente superior
servidor

11. Você já trabalhou com carteira assinada? *

Marcar apenas uma oval.

$\int \operatorname{Sim}$

Não

12. Qual a escolaridade de sua mãe? * Marcar apenas uma oval.

não estudou em escola regular

fundamental incompleto

fundamental completo

médio incompleto

médio completo

superior incompleto

superior completo

pós graduada

13. Qual a escolaridade de seu pai? *

Marcar apenas uma oval.

não estudou em escola regular

fundamental incompleto

fundamental completo

médio incompleto

médio completo

superior incompleto

superior completo

pós graduada

Powered by 